\title{
Auroral bright spot sequence near 1400 MLT: Coordinated optical and ion drift observations
}

Article

Published Version

Sandholt, P. E., Lockwood, M., Lybekk, B. and Farmer, A. D. (1990) Auroral bright spot sequence near 1400 MLT:

Coordinated optical and ion drift observations. Journal of Geophysical Research, 95 (A12). pp. 21095-21110. ISSN 0148-0227 doi: https://doi.org/10.1029/JA095iA12p21095 Available at https://centaur.reading.ac.uk/38852/

It is advisable to refer to the publisher's version if you intend to cite from the work. See Guidance on citing.

Published version at: http://dx.doi.org/10.1029/JA095iA12p21095

To link to this article DOI: http://dx.doi.org/10.1029/JA095iA12p21095

Publisher: American Geophysical Union

All outputs in CentAUR are protected by Intellectual Property Rights law, including copyright law. Copyright and IPR is retained by the creators or other copyright holders. Terms and conditions for use of this material are defined in the End User Agreement.

www.reading.ac.uk/centaur 
Central Archive at the University of Reading

Reading's research outputs online 
AURORAL BRIGHT SPOT SEQUENCE NEAR 1400 MLT: COORDINATED OPTICAL AND ION DRIFT OBSERVATIONS

P.E. Sandholt, 1 M. Lockwood, ${ }^{2}$ B. Lybekk, ${ }^{1}$ and A.D. Farmer ${ }^{2}$

Abstract. Optical observations of a dayside auroral brightening sequence, by means of all-sky TV cameras and meridian scanning photometers, have been combined with EISCAT ion drift observations within the same invariant latitude - MLT sector. The observations were made during a January 1989 campaign by utilizing the high $F$ region ion densities during the maximum phase of the solar cycle. The characteristic intermittent optical events, covering $\sim 300 \mathrm{~km}$ in east-west extent, move eastward (antisunward) along the poleward boundary of the persistent background aurora at velocities of $\sim 1.5$ $\mathrm{km} \mathrm{s} 1$ and are associated with ion flows which swing from eastward to westward, with a subsequent return to eastward, during the interval of a few minutes when there is enhanced auroral emission within the radar field of view. The breakup of discrete auroral forms occurs at the reversal (negative potential) that forms between eastward plasma flow, maximizing near the persistent arc poleward boundary, and strong transient westward flow to the south. The reported events, covering a $35 \mathrm{~min}$ interval around $1400 \mathrm{MLT}$, are embedded within a longer period of sjmilar auroral activity between 0830 (1200 MLT) and 1300 UT (1600 MLT). These observations are discussed in relation to recent models of boundary layer plasma dynamics and the associated magnetosphere-ionosphere coupling. The ionospheric events may correspond to large-scale wavelike motions of the low-latitude boundary layer (LLBL)/plasma sheet (PS) boundary. On the basis of this interpretation the observed spot size, speed and repetition period ( $10 \mathrm{~min})$ give a wavelength (the distance between spots) of $\sim 900 \mathrm{~km}$ in the present case. The events can also be explained as ionospheric signatures of newly opened flux tubes associated with reconnection bursts at the magnetopause near 1400 MLT. We also discuss these data in relation to random, patchy reconnection (as has recently been invoked to explain the presence of the sheathlike plasma on closed field lines

\section{${ }^{1}$ Department of Physics, University of 0s 10, Norway \\ ${ }^{2}$ Rutherford Appleton Laboratory, Chilton, United Kingdom} $\begin{array}{lr}\text { Copyright } & 1990 \\ \text { Geophysical Union. } & \end{array}$

Paper number 90 JA01369 0148-0227/90/90 JA-01369

$\$ 05.00$ in the LI.BL). In view of the lack of IMF data, and the existing uncertainty on the location of the open-closed field line boundary relative to the optical events, an unambiguous discrimination between the different alternatives is not easily obtained.

\section{Introduction}

The increased interest in dayside ionospheric phenomena in recent years is motivated by the general question of solar wind-magnetosphere-ionosphere interaction. The basic physics of the mass, momentum and energy transfer processes in the interface region between the shocked solar wind (magnetosheath) and the dayside magnetosphere-ionosphere system is a matter of controversy at present (e.g. Lundin, 1988; Heikkila et a1., 1989; Cowley, 1986). The two major model categories in this respect are the different merging/reconnection models and the so-called boundary layer dynamo model. In addition, Kelvin-Helmholtz waves have been predicted on the flanks of the magnetopause and on the low-latitude boundary layer (LLBL)/plasma sheet (PS) interface, and may transfer momentum across these boundaries.

Magnetic field line merging at the dayside magnetopause may occur in a quasi steady state or a transient manner. In situ evidence of both mechanisms has been provided through the ISEE and AMPTE missions (e.g.) see review by Elphic (1988); Saunders (1989)). During recent years a great effort has been made to identify ionospheric signatures of transient, patchy merging/reconnection, to a large extent based on predictions from the flux transfer event concept of the process as presented by Russell and Elphic (1979). Ionospheric evidence in favor of the flux transfer event (FTE) model has been documented by Sandholt et al. (1990), who observed auroral and ion drift signatures consistent with reconnected $\mathrm{flux}$ tubes convecting along the dayside polar cap boundary, as predicted by Cowley (1986) and Southwood (1987). These events had a repetition period of about $8 \mathrm{~min}$ when the interplanetary magnetic field (IMF) was continuously southward (Lockwood et a 1., 1989b). In addition, Nishida (1989a,b) has recently suggested how patchy, random reconnection can generate some of the observed features of the low-latitude boundary layer. However, in view of the diversity of dynamical phenomena near the magnetopause, including pressure pulses, KelvinHelmholtz waves and FTEs, and the present 
limited knowledge of the magnetic field line mapping between the different dayside auroral regions and the magnetospheric boundaries, the problem of identifying ionospheric FTE signatures is not a simple one. Furthermore, the problem of distinguishing between the cusp and the cleft auroral emissions, owing to a gradual change of the electron precipitation parameters from one region to the other (cf. Newell and Meng, 1988, Figure 8), adds to the complexity of the identification problem.

Whereas magneto-fluid dynamics is the basis of the reconnection models (e.g. Song and Lysak, 1989) a plasma kinetic point of view is utilized in the boundary layer dynamo model (Lundin, 1988). In this description, boundary layer plasma flow (or pressure) is converted into electric energy (polarization) in the interaction region, with subsequent energy dissipation in the acceleration region of auroral particles and the ionosphere. We also note the interesting possibility that the boundary layer dynamo is activated by plasma entry through "holes" in the magnetopause associated with local disruptions of the Chapman-Ferraro current (Lundin, 1988). The current disruption is usually described in terms of merging/reconnection (e.g., Song and Lysak, 1989). Thus, neither of the two major model categories seems to exclude the other (cf. Cowley, 1986: Baumjohann and Paschmann, 1987).

In situ observations indicate that the boundary layer can be highly structured and variable (e.g., Sckopke et al., 1981; Lundin, 1984; Elphic, 1988; Saunders, 1989). A corresponding structure and variability of dayside auroral forms has been observed by satellite imagery (e.g., Meng and Jundin, 1.986) and by coordinated ground-satellite observations of auroral precipitation and optical emissions (cf. Sandho1t et al., 1989).

Sckopke et al. (1981) found that the boundary layer plasma often occurs as a serjes of "blobs" of high-density magnetosheathlike plasma separated by plasma of magnetospheric character. Cowley (1982, 1984) argued that at least some of these "blobs" were associated with FTEs. Lundin (1988) agreed with the interpretation that the plasma "blobs" in the boundary layer and FTEs are likely to be "aspects of the same phenomenon."

The possible role of Kelvin-Helmboltz waves at the LLBL/PS interface as a generator of small-scale magnetic and electric field structure and auroral emissions near the poleward edge of the auroral oval has been investigated by Bythrow et a1. (1986). A similar explanation of localized auroral bright spots, observed by the UV imager on the Viking satellite, has been proposed by lui et al. (1987, 1989) and T.A. Potemra, H. Vo, D. Venkatesan, L.L. Cogger, R.E Erlandson, L.J. Zanetti, P.F. Bythrow, and B.J.
Anderson (Periodic auroral forms and geomagnetic field oscillations in the 1400 MLT region, submitted to the Journal of Geophysical Research, 1989).

Ground-based remote sensing techniques, such as radars and optical instruments, with their ability to monitor continuously the temporal and spatial variations of, e.g., particle precipitation and ionospheric ion drift/electric field in the cusp/cleft regions, are expected to be powerful tools for extracting new information on the dynamical behavior of the magnetopause boundary regions and the associated electromagnetic coupling to the ionosphere.

At sunspot maximum, the ionospheric projection of the magnetopause boundary can be observed near noon by using the EISCAT incoherent scatter radar Polar experiment (van Eyken et al., 1984; willis et al., 1986). In this paper the EISCAT ion drift observations are combined with optical observations from Svalbard of cusp/cleft auroral emissions. We focus on certain auroral events near 1400 MLT that are in many respects similar to the dayside breakup event phenomenon reported earlier (cf. Sandholt et al., 1990), a1though there are differences between the ion drift patterns.

\section{Data Presentation}

The optical observations were obtained by a four-channel meridian scanning photometer system and two al1-sky TV cameras, one intensifier-silicon-intensifier target (ISIT) camera with maximum sensitivity between 400 and $500 \mathrm{~nm}$ and a charge-coupled device (CCD) camera with $630.0 \mathrm{~nm}$ filter, operated at Ny Alesund, Svalbard (cf. Figure 1). The meridian scanned by the photometers (approximately the magnetic meridian) every $18 \mathrm{~s}$ as well as the useful field of view of the TV cameras (a circle of radius $500 \mathrm{~km}$ ) are marked in Figure 1 .

The ion drift observations were obtained by operating the EISCAT UHF radar in the beam-swinging mode "Polar" (version SP-UK-POLH) that permitted drift vectors to be derived at 25 gates between $71^{\circ}$ and $78^{\circ}$ invariant latitude every $2.5 \mathrm{~min}$. The locations of drift vector gates $1,5,10$, 15, 20, and 25 are marked in Figure 1 . These are midway between the two azimuths on the L-shells where the EISCAT observations are made. Compared to the similar combination of optical - ion drift data sets presented by Lockwood et al. (1989a, b) and Sandholt et al. (1990), the radar data used in this paper are significantly improved in the sense that they cover a much larger latitudinal range toward north and the gate separation is smaller ( $37 \mathrm{~km}$ versus $75 \mathrm{~km}$ ).

Figures $2 \mathrm{a}$ and $2 \mathrm{~b}$ show stacked photometer traces for the time period 10151050 UT (1345-1420 MLT) of auroral emissions at 630.0 and $557.7 \mathrm{~nm}$, respective- 


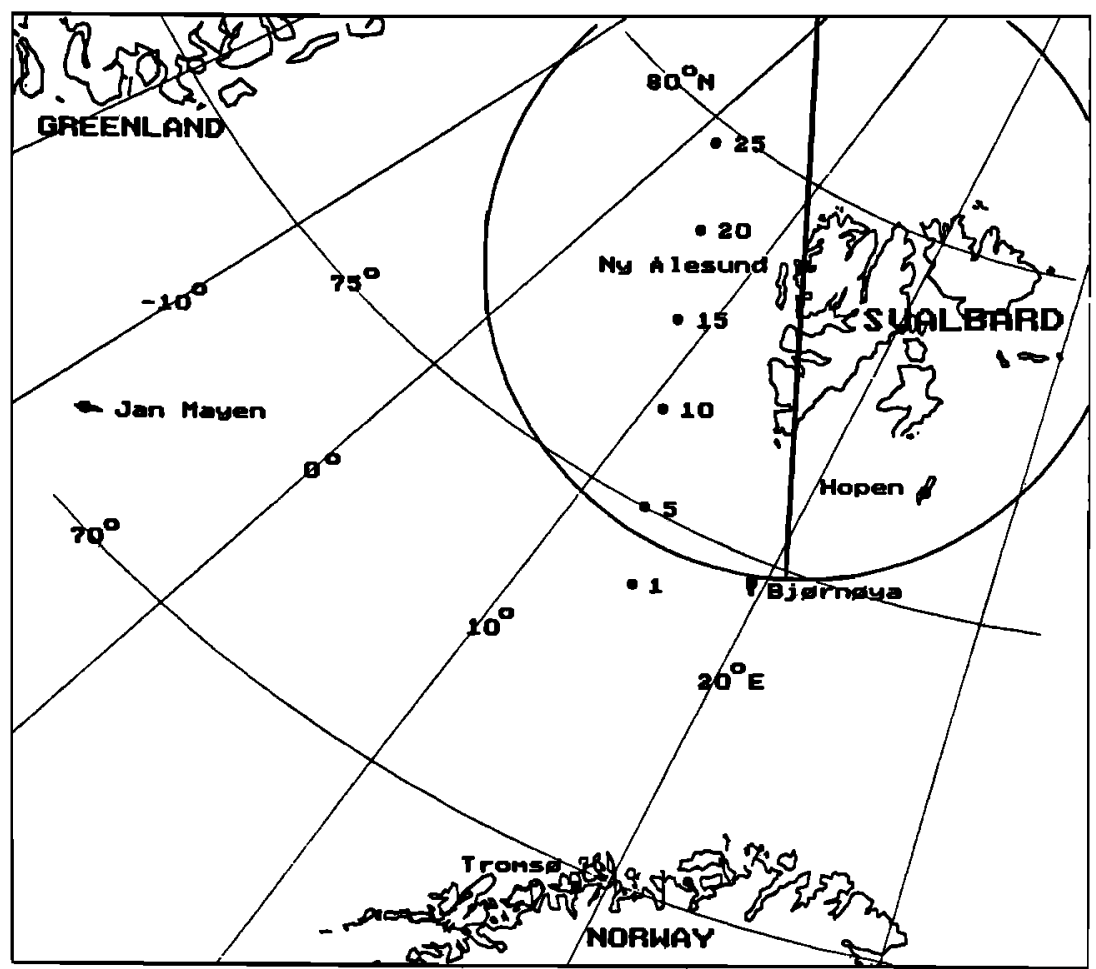

Fig. 1. Map including Svalbard and North Norway with the sites of the EISCAT radar (near Troms $\phi$ ) and the optical installations in Ny Alesund. Also indicated are the photometer scanning direction and the approximate useful field of view of the all-sky TV cameras, as well as the geographic location of six of the 25 radar gates used in the EISCAT POLAR program (cf. Plate 1 and Figure 4).

1y. Positive zenith angles are defined to be to the north of Ny Alesund. We notice a high $630.0 \mathrm{~nm}$ intensity (5-10 kR) within a belt a few degrees wide with the poleward boundary near zenith. The other characteristic feature is the sequence of four events $(1015,1025,1040$, and 1050 UT), each marked by intensification within the background arc and subsequent poleward motion, i.e., the transient auroral form separates from the persistent arc. Corresponding, although generally more short-1ived, intensifications and poleward motions are seen in the green line emission (Figure 2b). The maximum green line intensity is highly variable from case to case, during the present sequence between $\sim 1$ and $8 \mathrm{kR}$.

Figure 3 shows a sequence of nine $630.0 \mathrm{~nm}$ all-sky TV images between 1027 and 1035 UT, i.e. covering the second transient event in Figure 2. In Plate 1 the sequence of digitized images has been mapped down to the Earth's surface, assuming an emission altitude of the $630.0 \mathrm{~nm} 1 \mathrm{ine}$ of $250 \mathrm{~km}$. The coordinate system is north geographic latitude and east geographic longitude. The photometer scanning direction is marked in the figures. The location of EISCAT radar gates $10,15,20$, and 25 (cf. Figure 4) are marked by solid dots in the frames.
On those frames for which the image was taken within $30 \mathrm{~s}$ of a radar flow measurement, the derived flow vectors are also shown. The altitudes of the corresponding scattering volumes are 380,470 , 565 , and $662 \mathrm{~km}$, respectively. We notice a steady eastward motion of the region of most intense emission, shown by dark color in Plate 1. This "bright spot," covering a longitudinal extent of $\sim 300$ $\mathrm{km}$, is passing the photometer scanning plane within 1028-1031 UT. The corresponding peak in the photometer intensities is easily identified in figures $2 a$ and $2 \mathrm{~b}$. An average velocity of $1.4 \mathrm{~km} \mathrm{~s}-1$ of the eastward moving bright region between 1027 and 1032 UT was derived from Plate 1. This is similar to the derived eastward flow speed at the same time, within the bright spot. At later times (after 10.32.30), plasma flow speeds increase to near $3 \mathrm{~km} \mathrm{~s}$.

The background aurora recorded between the events, for example, in the interval between 1030 and $1040 \mathrm{UT}$, show very high red 1 ine intensity $(5-10 \mathrm{kR})$ and weak green line intensity, i.e., I630.0/I557.7 $\mathrm{nm} \gg$ 1. An eastward moving "bright spot", as exemplified in Figure 3 and Plate 1, is seen in each of the other three events marked in the photometer traces in Figure 2. The event sequence 


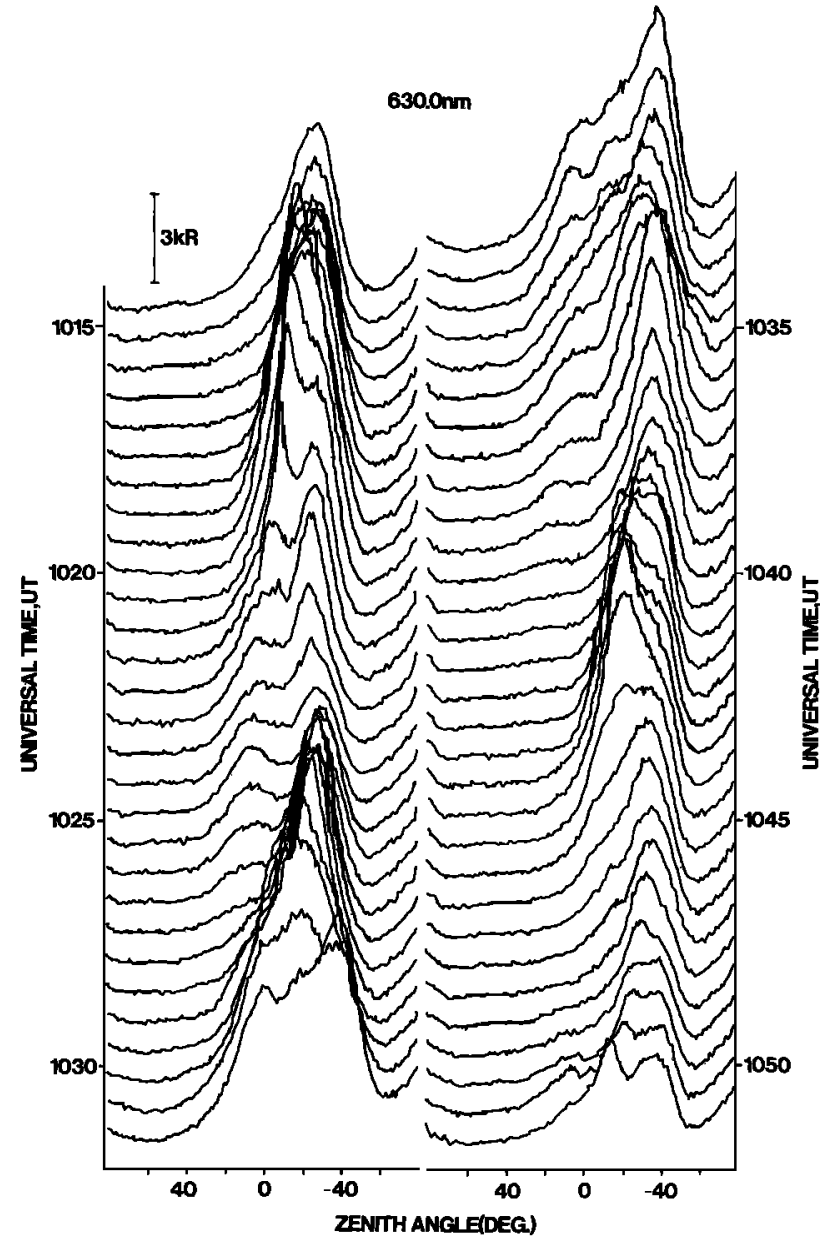

Fig. 2a. Stacked plot of $630.0 \mathrm{~nm}$ scanning photometer traces for the 1015-1050 UT interva1 on January 9, 1989.

presented here is part of a longer sequence recorded between $\sim 0830$ ( $12 \mathrm{MLT})$ and $\sim 1230$ UT (1600 MLT).

The ion drift vectors observed during the 1025-1035 UT optical event are shown in full in Figure 4. From Figure 4 we infer that the persistent arc of $630.0 \mathrm{~nm}$ emission (Figures $2 a$ and 3 , and Plate 1) is colocated with a region of enhanced eastward flow at typical speeds of $\sim 3 \mathrm{~km}$ $s^{-1}$ after 1033 UT. Significantly lower velocities are observed both poleward and equatorward of this channel of enhanced flow. A marked deviation from this general pattern occurred between 1023 and $1030 \mathrm{UT}$, when strong westward flow is seen at auroral latitudes, with the eastward flow located further north. A pronounced reversal between strong eastward and westward flows is seen near 1028 UT, located close to the latitude of maximum auroral emission, which at this time included discrete forms (cf. green line intensity peak in Figure 2b). At this time the most intense aurora was located at the longitude of the radar field of view, slightly to the west of Svalbard (cf.Figures 1 and 3 and Plate 1 ).
Between 1030 and 1035 UT, the bright auroral region (I630.0 $\mathrm{nm} / 1557.7 \mathrm{~nm} \gg>1$ ) moved steadily eastward, near the poleward boundary of the persistent arc, but now far outside the radar field of view. A similar, but weaker, flow reversal occurred at lower latitude, near 1041 UT, corresponding to the next optical event (cf. Figure 2a).

The EISCAT flow data are derived using the beam-swinging technique which makes assumptions about the temporal and spatial variability of the $f$ low in the radar field of view (Willis et al., 1986). Specifically, it is assumed that the flow is uniform between the two beam directions employed and that it varies 1 inearly with time over each 5-min beamswinging cycle. Both these assumptions may be invalid during the transient, localized auroral events described in this paper. To investigate the integrjty of the derived vectors shown in Figure 4, we can study the ion temperatures observed by EISCAT, as shown in Plate 2. The first point to note is that there are some, but generally not many, 5-min oscillations in the $T_{\text {, contours. The data }}$ shown are for both the radar azimuths, and hence a spatial gradient in flow (and hence $T_{i}$ ) between the two look-directions would manifest itself as a 5-min oscillation (the cycle period of the radar scan between the two azimuths). Exceptions to

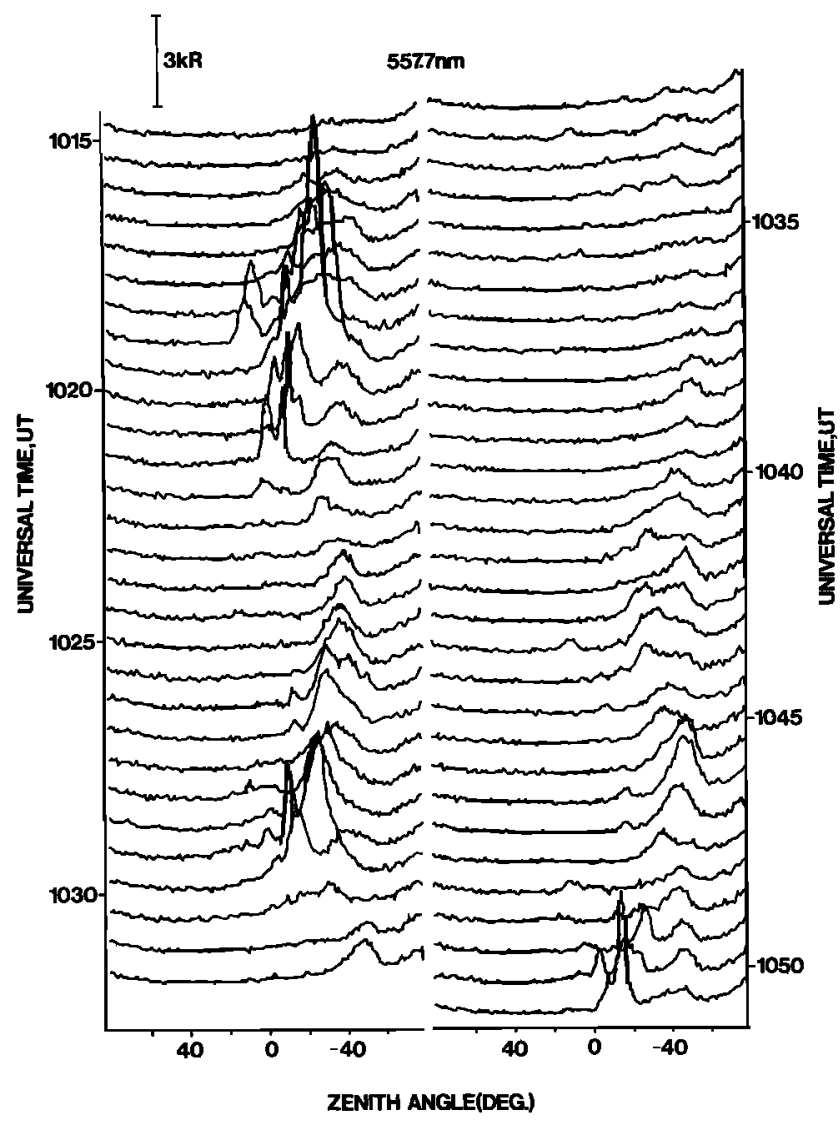

Fig. 2b. Same as Figure 2a, except for the $557.7 \mathrm{~nm}$ aurora. 


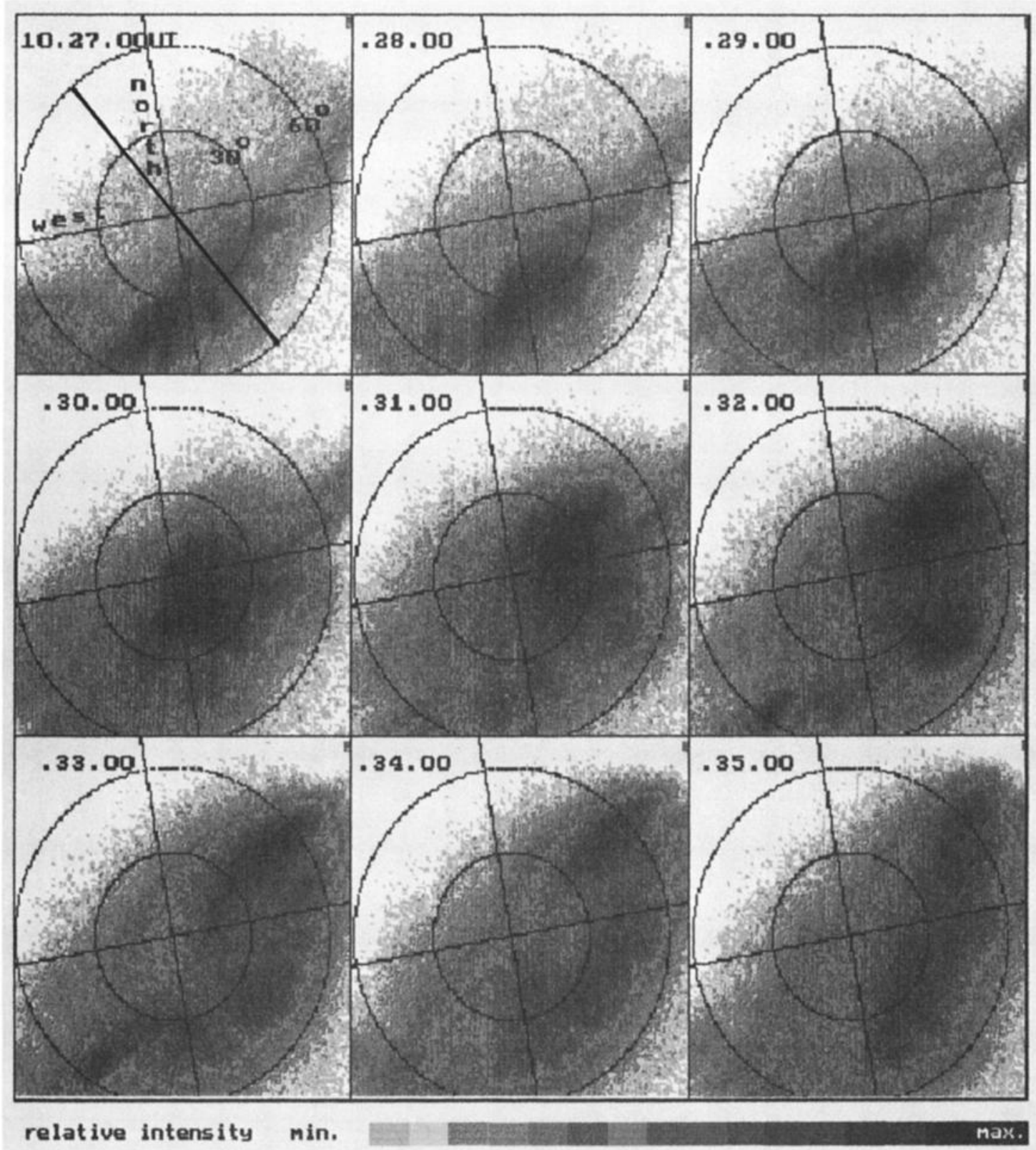

Fig. 3. Al1-sky TV picture sequence of $630.0 \mathrm{~nm}$ aurora for 1027-1035 UT on January 9,1989 , in zenith angle - geographic azimuth coordinates. Photometer scanning direction is marked by solid line.

this are at $\lambda=73.5^{\circ}$ and 1038 UT (when $T_{i}$ and hence ion flows are appreciably lower at azimuth 2 , i.e., the easterly look direction) and at both $\lambda=72.5^{\circ}$ and $\lambda=75^{\circ}$ at 1033 UT (when again flows are lower at the easterly azimuth). Genera1$1 y$, the spatial assumption seems to hold well elsewhere. It is noted, however, that spatial gradients probably do cause errors in the vector determination during the optical event near 1027 UT.

Plate 2 shows a band of enhanced $T_{i}$ ( $)$ $6000 \mathrm{~K}$ ) near $\lambda=76^{\circ}$ at 1015 , which moves poleward to near $77^{\circ}$ at 1035 . This can be associated with the channel of eastward flow shown in Figure 4. Using a simple form of the ion energy balance equation (with dominant ion-neutral frictional heating and neglecting neutral winds) the $T_{i}$ values require flows exceeding $2.5 \mathrm{~km}$ $s^{1}$, roughly consistent with the flow speeds derived in this flow channel by the beam-swinging technique. The westward flows at the onset of the event are shown in Plate 2 to drive ion temperatures of about $4400 \mathrm{~K}$, This requires flows of order $2 \mathrm{~km} \mathrm{~s}^{-1}$, which is consistent with the speeds shown in Figure 4 in this region (to within an uncertainty caused by the neutral winds). A third major feature in Plate 2 is a strong enhancement in $\mathrm{T}_{\mathrm{i}_{0}}$ (to values exceeding $6000 \mathrm{~K}$ ) at $\lambda=$ 


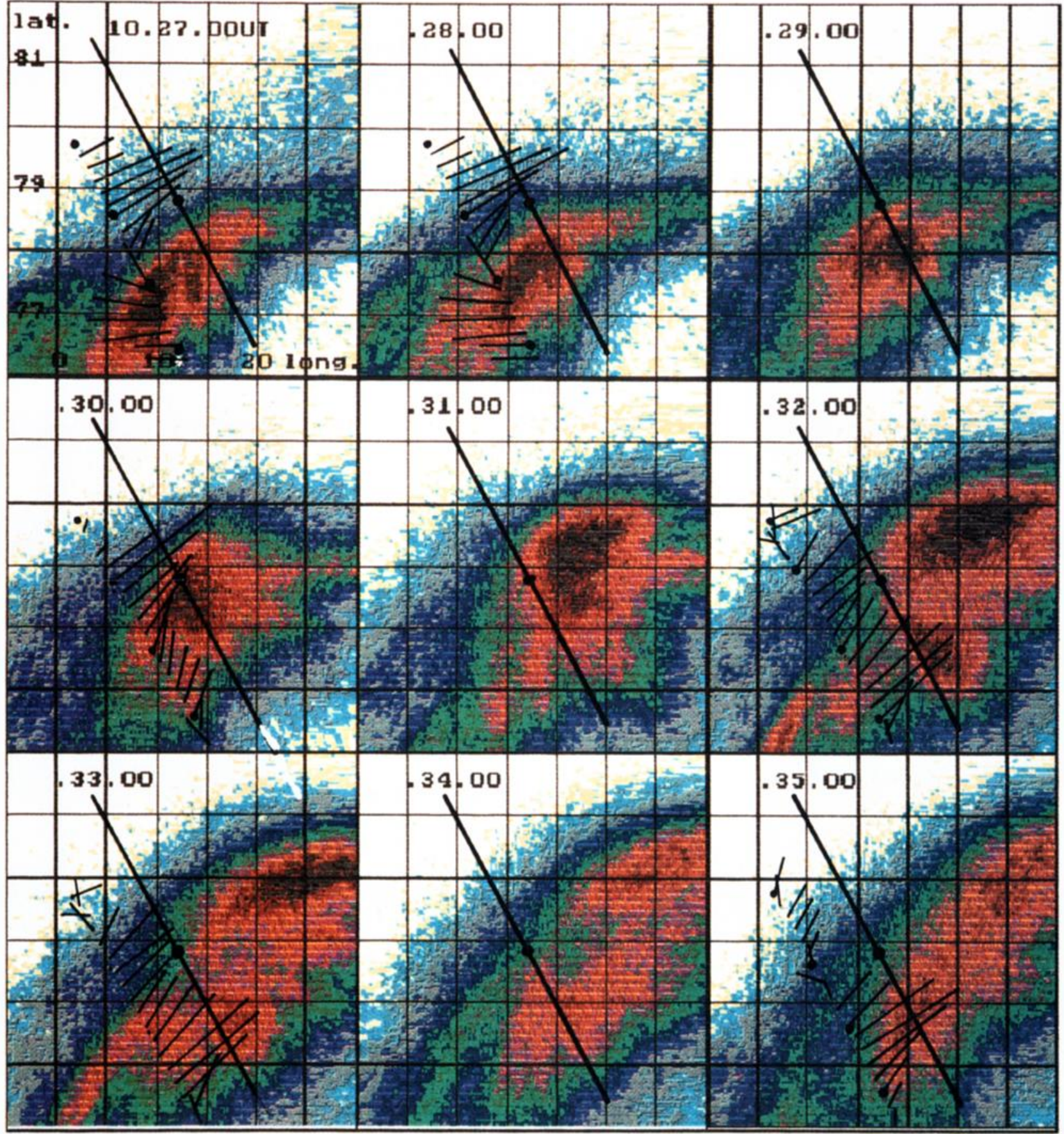

relative intensity min.

Plate 1. Auroral picture sequence in Figure 3 mapped down from an assumed emission altitude of $250 \mathrm{~km}$ to the earth's surface and plotted in geographic latitude-1 ongitude coordinates. The optical site is marked by solid dots. Ion drift vectors in gates 10-25 have been superposed on the $1027,1028,1030,1032,1033$, and 1035 UT pictures using EISCAT data for $1027: 30,1027: 30,1030: 00,1032: 30,1032: 30$, and 1035:00, respectively. No flow data were taken within $30 \mathrm{~s}$ of the 1029,1031 , or 1034 images. Solid 1 ines mark the photometer scanning direction. 


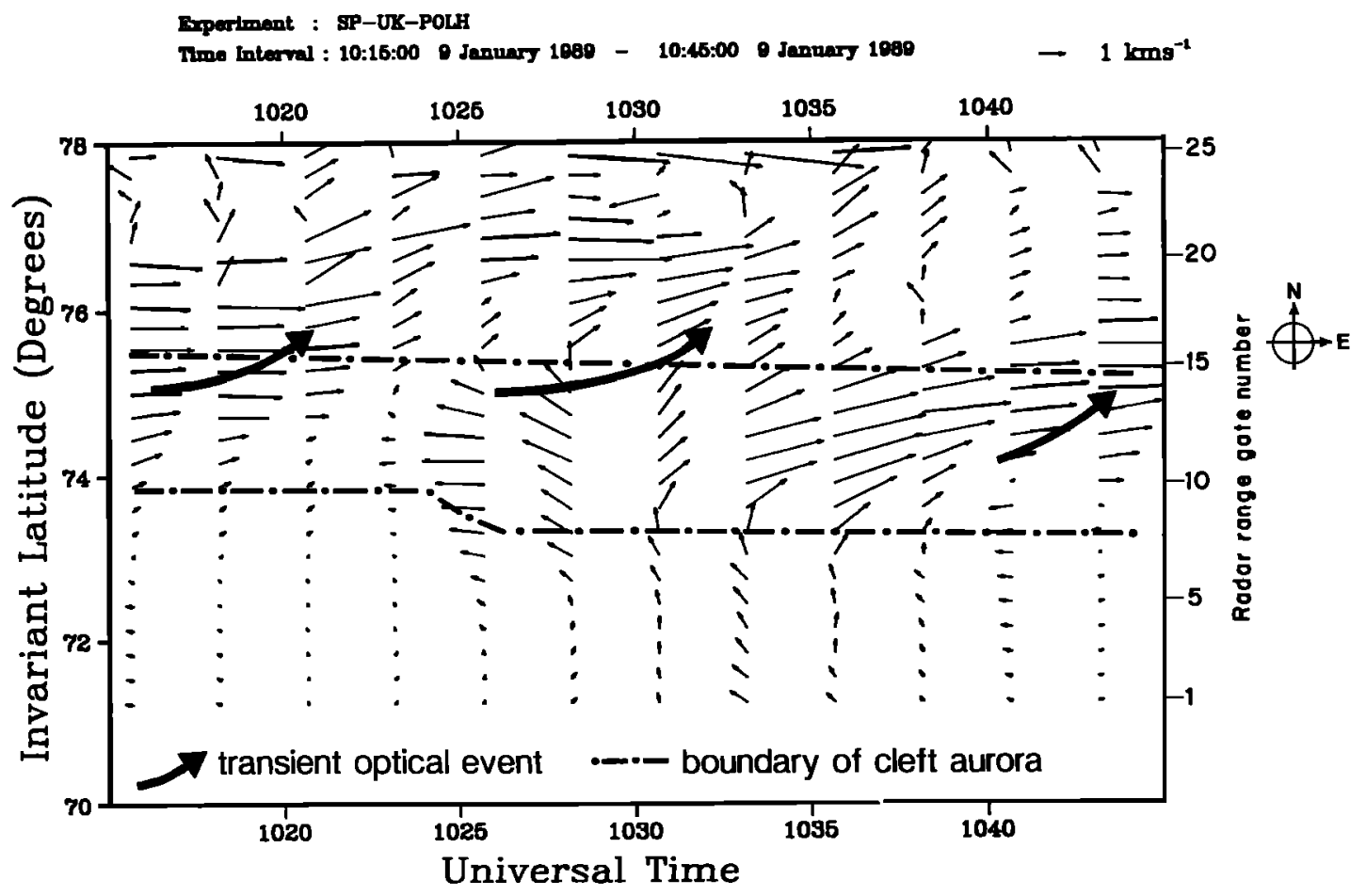

Fig. 4. Ion drift vectors at 25 gates within $71^{\circ}-78^{\circ}$ invariant 1 atitude for the 1015-1045 UT interval on January 9, 1989. The locations of the radar gates in relation to svalbard and the optical recording site are shown in Figure 1 and Plate 1. The latitudes of the discrete 557.7nm and background $630.0 \mathrm{~nm}$ aurorae have been mapped assuming altitudes of 130 and $250 \mathrm{~km}$, respectively.

73-75 after 1035 UT, which subsequently drifts slowly north. This ion temperature enhancement can be associated with the eastward ion flow channel in Figure 4. Again, the ion temperatures ( $7000 \mathrm{~K}$ ) are consistent with the derived ion flows ( $\mathrm{V}>2.5 \mathrm{~km} \mathrm{~s}^{-1}$ ).

The ion temperature analysis assumed that the ion velocity distribution function was Maxwellian; however, for the large flows shown in Figure 4, it will tend to an anisotropic and toroidal form, especially at the lower altitudes where ion-neutral collisions are high (st. Maurice and Schunk, 1979; Lockwood and Winser, 1988; Lockwood et al., 1989c). The supersonic ion drifts required to give non-Maxwellian ion velocity distribution generally occurred at $\lambda=74^{\circ}-76^{\circ}$, for which altitudes are $380-510 \mathrm{~km}$. At these altitudes ion-ion collisions are important and tend to destroy the nonMaxwellian form produced by the ionneutral collisions (which are still, however, effective because the ion temperature is considerably elevated). Consequently, deviations from Maxwellian, isotropic distributions will be present, but not as markedly as at lower altitudes. We here show only data for Maxwe1$1 \mathrm{ian}$ analysis and note that ion temperatures may be somewhat overestimated (by up to an estimated $20 \%$ ) as a result (Suvanto et al., 1989).

Lastly, we note that the observed ion temperatures in the reversal between the westward flows and the eastward flow channel poleward of it at 1025-1028 (where $630 \mathrm{~nm}$ enhancements were observed) are considerably greater than would be predicted from the vector data. This shows that this flow reversal is much more shearlike than it appears in the vector data. The smoothing of shears in beam-swinging data has been simulated by Lockwood et a1. (1988). We conclude that the ion temperatures expose some limitations in the ion flow data, but that the major features are broadly correct.

\section{Discussion}

The great advantage of the present optical and ion drift observations compared to earlier similar studies (cf. Sandholt et al., 1990) is the upgraded EISCAT ion drift program which provided improved gate separation and latitudinal coverage of the cusp and cleft auroral regions near midday.

The 35 min interval of data presented here is typical of the 0830 (1200 MLT) to 1130 UT ( 1500 MLT) period on this day. A detailed analysis of one of the events 


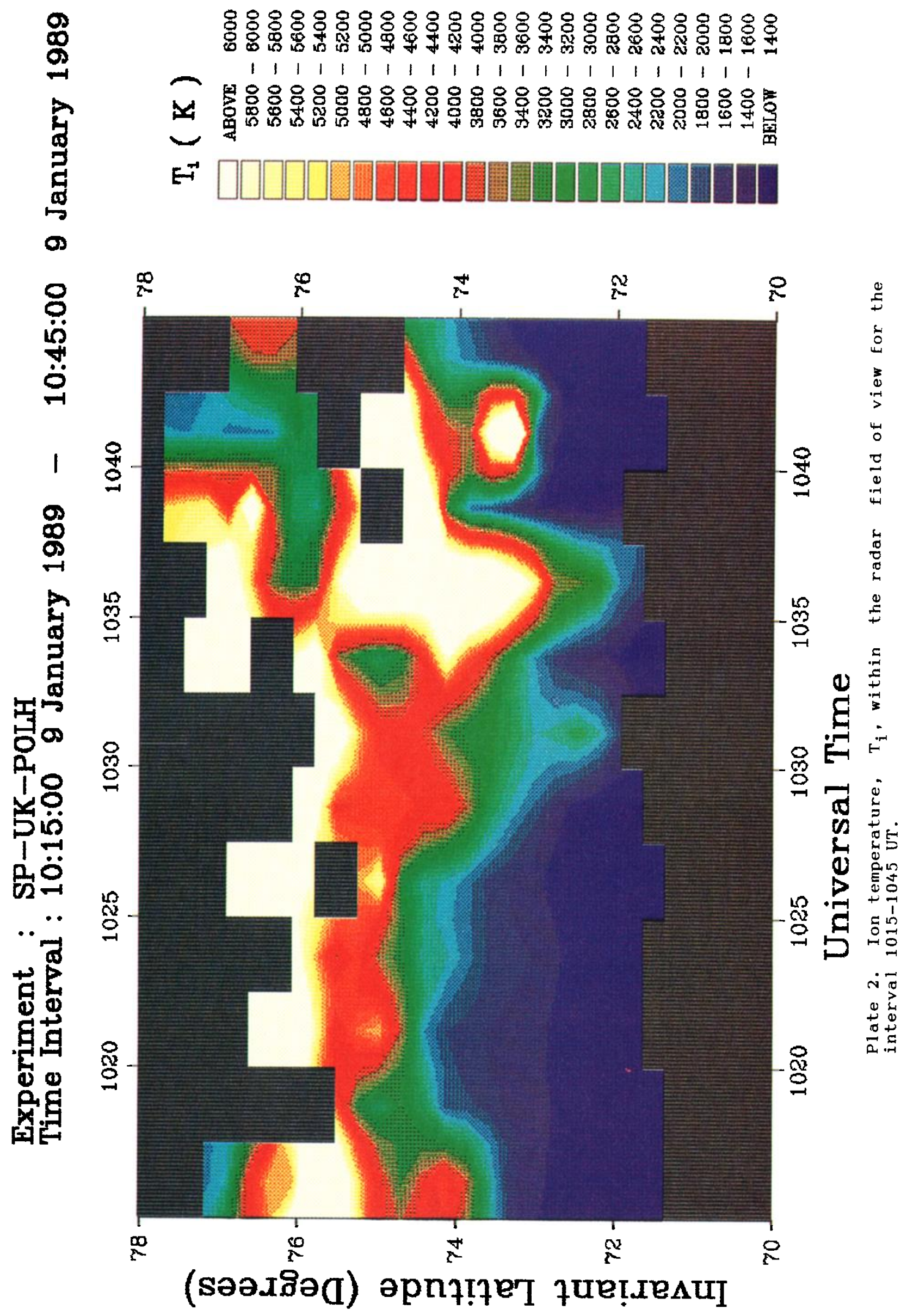


close to magnetic noon will be presented elsewhere (Lockwood et a1., 1990). The typical features of the events are as follows:

1. A channel of strong $\left(\sim 3 \mathrm{~km} \mathrm{~s}^{-1}\right)$ eastward ion flow is colocated with the persistent cleft aurora;

2. A swing from eastward to westward flow is associated with the onset of the optical events (a reservation is due to the radar technique);

3. The transient optical events, often including active, discrete forms, are located near the convection reversal between eastward and westward flow channels;

4. The optical events, covering $\sim 300$ $\mathrm{km}$ in longitudinal extent, move eastward along the persistent arc poleward boundary;

5. A series of four events is seen within the selected $35-m i n$ interval.

The first of the events is not as clearly marked in the ion drift data as the others. This might be explained by the al1-sky TV data which show this optical event to appear near the photometer scanning plane, i.e. to the east of the radar field of view (see Figure 1 ).

\section{The plasma source identification problem}

One serious problem that strongly influences the interpretation of such dayside auroral phenomena is the difficulty in distinguishing between the different magnetosphere boundary regions that correspond to the various auroral emissions. Auroral forms with only slightly different spatial location and spectral properties may map to widely separated magnetospheric plasma population, such as the exterior cusp, LLBL, boundary plasma sheet (BPS), and the plasma mantle. Combined ion and electron precipitation data from satellites in polar orbit, or possibly from rockets, are necessary in order to make the distinction between the cusp and the cleft/LLBL or other boundary plasmas (se the introduction).

At 1400 MLT, the local time of the present events, the statistical occurrence probabilities of the three precipitation categories cusp only, cusp poleward of the cleft and cleft only are $15 \%, 5 \%$, and $62 \%$, respectively, according to Newe 11 and Meng (1989). This result, in combination with the observed eastward (antisunward) flow at the latitude of the persistent background aurora, may indicate a LLBL source of the present optical/ion drift events. Another set of observations that seem to support this interpretation is referred to below. On the other hand, the large red line intensities combined with high red to green line ratios in the background emission means that a cusp origin of the auroral particles cannot be excluded.

On the basis of AMPTE-UKS (United
Kingdom Satellite) electron observations near the equatorial dayside magnetopause Chaloner et a1. (1987) separate between different plasma populations, including the LLBL electrons that originate in the magnetosheath and the "magnetosphere halo" on the inner side of the LLBL, containing a mixture of electrons from the magnetosphere and an energized magnetosheath component. They suggest that the magnetosphere "halo", rather than the LLBL, is responsible for the dayside aurora.

\section{The LLBL dynamo mode 1}

The optical event sequence discussed in this paper is very similar to that analyzed by Sandholt et al. (1989). These authors presented a pass of the HILAT satelite through cusp/cleft structures on December 10, 1983, and coincident auroral photometer scans. The satellite data provided a latitude profile of field-aligned current which showed the cusplike electron precipitation zone to be associated with a downward region 1 current with superposed smaller scale current structures. The much weaker upward current further north may be identified as the mantle current (cf. Bythrow et al, 1988). The major part of the dayside region 1 current is considered to map to the dayside low-latitude boundary layer, with some portion mapping to the entry layer in the outer magnetosphere (cf.'Erlandson et al., 1988). Thus, assuming the persistent auroral arc near 1400 MLT (Figure 2) maps to the dayside LLBL, the transient events that move along the poleward boundary of this arc may map to the LLBL outer edge.

Furthermore, the strong westward flow to the south of the transient $557.7 \mathrm{~nm}$ optical events might correspond to a sunward flow at lower radial distances in the boundary layer. A tempting interpretation is that this phenomenon is related to sunward return flow on the inward side of intruding plasma filaments as sketched by Lundin and Evans (1985), in their Figure 8. According to this description, the polarization of the boundary layer plasma gives rise to a dynamo process that drives a three-dimensional current system with associated energy dissipation in the ionosphere. Field-aligned potential drops can be activated locally within the upward flowing current component, with subsequent discrete auroral structures near the boundary between eastward and westward ionospheric plasma flow. This prediction is consistent with the present optical and ion drift observations. A short period (few minutes) with localized, active discrete aurora within the $\sim 10 \mathrm{~min} 1$ ifetime of the events is often observed. From the 1025-1035 UT event (Figures 2 and 3 and Plate 1 ) we notice that an eastward moving patch of strong red line emission (mean velocity 
$1.4 \mathrm{~km} \mathrm{~s} \mathrm{~s}^{-1}$ ) was observed for about $5 \mathrm{~min}$ after the disappearance of the discrete aurara. Thus, the 1030-1035 UT period of the transient event was characterized by rather unaccelerated magnetosheath1ike plasma. The red line intensities near 1400 MLT (5-10 kR) are significantly higher than in the 1200 MLT aurora observed this same day. Earlier observations of a maximum in particle precipitation and field-aligned current intensities near 1400-1500 MLT, have been reported by e.g. Evans (1985) and Iijima and Potemra (1978, Figure 14), respectively.

It is noted that after 1035 the motion of the auroral patch is significantly slower than the high-speed ion flow (1.4 $\mathrm{km} \mathrm{s} \mathrm{s}^{-1}$ versus $3 \mathrm{~km} \mathrm{~s}^{-1}$ ) observed before and after the optical event passed

through the radar field of view (cf. Figures 3 and 4 and Plate 1). This might possibly be explained by a boundary layer dynamo under strong internal load, associated with efficient momentum exchange from the injected to the local plasma in case of similar densities of the two plasma components. The result will be a boundary layer plasma (injected and local plasmas) flowing at much reduced speed, with corresponding momentum/energy transfer to the ionosphere (cf. Lundin, 1988). The short interval of active, discrete aurora betweem 1027 and $1028 \mathrm{UT}$ may then correspond to an initial enhanced power transmission to the ionosphere, related to the plasma injection, before the dynamo is choked by increased internal (boundary layer) and external (ionospheric) loads. Corresponding changes in the ionospheric ion flow speed that should accompany such variations in the dynamo-efficiency may be seen in the present data.

A Kelvin-Helmholtz instability at the LLBL/PS interface is an additional candidate for generating the discrete aurora. This mechanism is particularly relevant if the ionospheric phenomenon maps to the near-tail low-latitude boundary layer. Note, however, that the LLBL/PS interface maps to the equatorward edge of the cleft aurora. This does not seem consistent with the location of the observed discrete aurorae near the poleward edge of the background $630-\mathrm{nm}$ aurora.

\section{Reconnection-related scenarios}

A marked feature of the observations which is not well explained by the above interpretation is the high-speed ion flow $\left(\sim 3 \mathrm{~km} \mathrm{~s}{ }^{-1}\right)$ in the cusp/cleft, which is much faster than the $630 \mathrm{~nm}$ auroral blob. The ion temperatures observed confirm that the high ion flow speeds are real.

With this background we will discuss the observations in relation to four different variants of the reconnection mode1. The indicated transient injection of sheathlike particles, the recurrence period and the spatial scale of the events are all consistent with an FTE interpretation.

In the first variant of the FTE interpretation the $630 \mathrm{~nm}$ blob is considered a remnant footprint of an FTE flux tube that was reconnected at an earlier time and is thus being dragged eastward by the tailward sheath flow. This would give a flow pattern like that illustrated in Figure $5 \mathrm{a}$, based on the Southwood (1987) mode1. This is a twin vortex pattern, with flow speeds in the center of the event being equal to the velocity of the event as a whole. However, severe inconsistencies with the observations appear. The eastward motion of the event should equal the eastward plasma flow in the 630-nm patch, which is not the case. One should see southwestward plasma flow (at low latitudes) before the blob arrives, in contrast to the observed northwestward flow. Finally, we see westward flow within the blob at 1025 - 1028 UT (cf. Plate 1). The conclusion from this is that the 630-nm blob does not seem to be a remnant of a burst of reconnection at an earlier time (UT) and an earlier MLT.

The next possibility to be examined is that the $630-\mathrm{nm}$ blob is a region of newly reconnected $f l u x$ which is expanding because enhanced reconnection continues, but at an MLT less than 1400. The predic-

A.
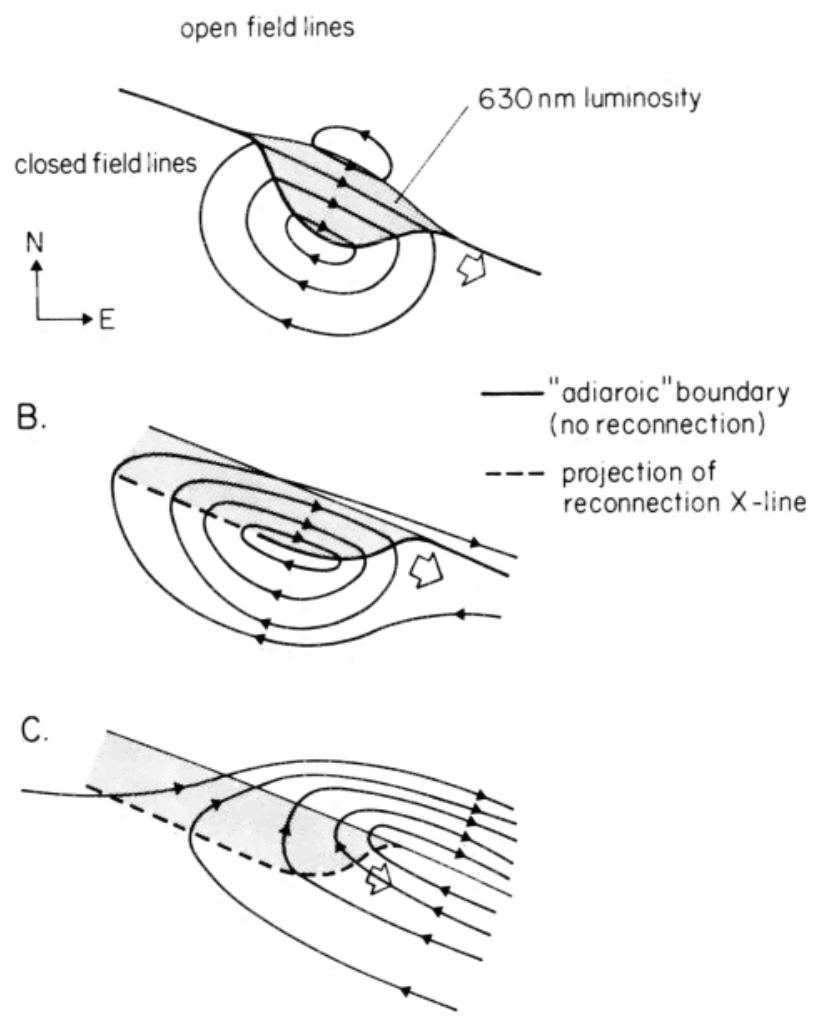

Fig. 5. Schematic transient ion flow configurations and relationship with auroral bright spots (hatched) near the open-closed field line boundary at 1400 MLT (cf. text). 
ted flows for this case are shown in Figure 5b. Now the eastward motion of plasma in the blob center is not necessarily equal to the eastward motion of the event leading edge. Again, we should initially see southwestward flow and no westward flow should exist inside the optical blob. This means that allowing for continuing reconnection on the noon side of the blob does not solve the problems with the first interpretation.

The third possibility to be considered is that reconnection continues at MLT as great as 1400 . The ion flow and the relationship with the optical event is illustrated in Figure 5c. Initially, we see westward flow ahead of the blob, with strong eastward flow poleward of it. At the radar longitude and inside the blob, plasma flow rotates with time from westward through northward back to eastward. Now eastward motion of the event reflects motion (or elongation to the east) of the $x-1$ ine and can be slower than the plasma motion. At any time reconnection can cease and we switch back to case 1 above. These last model predictions are more consistent with the observations. The conclusion is that if the optical/ion drift events are related to reconnection bursts at the magneiopause, inen iivey are taking place near $1400 \mathrm{MLT}$. The events cannot be reconnected near noon and then have moved around to 1400 MLT.

The above discussion invoked reconnec$t$ ion at $x-1$ ines on the magnetopause which were quite extensive (at least $1 \mathrm{R}_{E}$ in length). Nishida $(1989,1990)$ has recent $1 y$ proposed that during both northward and southward IMF there may be patchy reconnection at various short $X-1$ ines which are "random1y" dotted over the dayside magnetopause. The open field 1 ines produced can then re-connect to produce closed field lines. In fact, this is more likely to occur if the IMF is northward and there is no large-scale reconnection taking place at a long $x-1$ ine. This mechanism therefore would briefly open field lines, allowing sheath plasma to stream into the magnetosphere, and then close them again. Hence, this may explain the observations of sheathlike plasma on closed field lines within the LLBL. The observations presented here could be interpreted in terms of such a mechanism. The appearance of $630-n m$ luminosity would then be caused by the opening of a flux tube. It is necessary to postulate that the flux tube then convects westward under the influence of magnetic tension. The blob of luminosity may not clearly reflect the westward motion at this stage as it is expanding as reconnection proceeds.

If the field line is then closed again, it may begin to convect eastward under the influence of magnetic tension in the closed loop, or perhaps due to some momentum transfer across the magnetopause by, e.g., Kelvin Helmholtz waves.
The 1 uminosity may again not move eastward as fast as the convection if the precipitation fades first on the leading edge of the reclosed tube.

We do not propose that our data necessarily support this scenario, but it is interesting to note that it does offer an alternative explanation which involves reconnection.

\section{Summary}

Optical and ion drift observations related to a sequence of transient auroral events near $75^{\circ}$ invariant latitude and 1400 MLT have been discussed in terms of a simple dynamo model of the dayside low-latitude boundary layer, as well as different time dependent reconnection scenarios. A third interpretation, involving waves on the LLBL/PS boundary, is mentioned below ( $c f$. the Appendix). Two important reasons for the difficulty in discriminating between the different a ternatives are the existing uncertainty on the location of the open-closed field line boundary relative to the various auroral events and the lack of IMF data (R. Lepping, personal communication, $1990)$.

A most important feature of the dayside breakup events presented by Sandholt et a1. (1990) and Lockwood et a1

(1989a;b) that seems to favor the Southwood (1987) model of FTE-related ionospheric signatures is the observed westward (sunward) motion of the discrete auroral structures along the convection boundary in the 1200-1400 MLT sector, poleward of the background cusp or cleft arc during strongly positive IMF $\mathrm{B}_{\mathrm{Y}} \quad\left(\mathrm{B}_{\mathrm{Z}}<\right.$ $0)$. In addition to the auroral motion pattern relative to the background aurora, the interpretation of those events is based on their time duration and repetition frequency, observed to be related to the IMF orientation, and associated ion drift and magnetic signatures.

A new feature of the radar observations of the events presented in this paper is the intermittent swings from eastward (antisunward) to westward (sunward) flow, on the equatorward side of the transient optical events. The optical and ion drift observations are found to be consistent with reconnection bursts at the magnetopause, if they occur near 1400 MLT. Important characteristics of the present events are as follows:

1. A sequence of transient optical events with typical $10 \mathrm{~min} 1$ ifetime and a similar recurrence time is observed.

2. The background auroral arc is colocated with a channel of strong eastward (antisunward) plasma flow with maximum speed near $3 \mathrm{~km} \mathrm{~s}$.

3. The auroral events appear within the background arc and subsequently separate from it on the poleward side. 
4. The auroral events, covering $\sim 300$ $\mathrm{km}$ in longitudinal extent, move eastward (antisunward) with a velocity of $\sim 1.5 \mathrm{~km}$ $\mathbf{s}^{-1}$.

5. Localized, short-lived (few minutes or less) discrete aurora, activated by field-aligned acceleration, occur at the ion flow reversal (negative potential) associated with the transient swings from eastward to westward flow.

Finally, we note that in view of the close association of the auroral events and the intermittent occurrence of ion drift reversals, a Kelvin-Helmholtz instability, possibly related to plasma filaments in the boundary layer or at the LLBL/PS interface, may be involved. The appendix presents data from another day (January 7,1988 ) when optical events in the same local time sector, repeating every $10 \mathrm{~min}$, were associated with 5 -min period magnetic pulsations at lower latitudes. The similarities (optical periodicity, motion pattern) are sufficient to make us consider that LLBL/PS boundary waves may also be present in the cases discussed above, although the trigger mechanism for the boundary waves seem to be different in the two cases (cf, appendix).

Related to this, it is interesting to speculate that the characteristic shift between sunward and tailward ion drift during the events may occur as the different phases of the wave pass overhead, and the equatorward part of the radar field of view would then sometimes be in the projection of the LLBL and sometimes in the plasma sheet. Rostoker and Eastman (1987) describe how wave-like motions of the LLBL/PS boundary may involve protrusion of PS plasma into volumes of space normally occupied by the LLBL. Mapped into the ionosphere, this corresponds to poleward motion of the equatorward border of the region of discrete auroral activity.
It has been suggested that such boundary waves may modulate precipitating electrons ( $<1 \mathrm{keV}$ ) that are already present from the LLBL (cf. Potemra et a1., submitted manuscript, 1989) or the magnetosphere "halo" (cf. Chaloner et al., 1987) and thus give rise to auroral bright spot sequences like those reported here. Following this inter-pretation, the observed spot size $(\sim 300 \mathrm{~km})$, the $\sim 1.5 \mathrm{~km}$ $s^{-1}$ tailward speed, and the $10-m i n$ repetition period give a wavelength (distance between spots) of $\sim 900 \mathrm{~km}$, in the present case.

\section{Appendix}

As an appendix to the remark on a possible relationship between the reported auroral event sequence and magnetopause boundary waves, we present another case of photometer observations from the same local time sector that was associated with clean, large-amplitude $(\sim 100 \mathrm{nT})$ Pc 5 oscillations in the geomagnetic field.

Figure A1 shows H-component magnetograms from Ny $A l$ esund $\left(75^{\circ}\right.$ MLAT), Bjornфya ( $71^{\circ}$ MLAT), and Troms $\phi$ ( $67^{\circ}$ MLAT). The activity started with a sharp onset near 1055 UT, followed by harmonic oscillations (period of $5.5 \mathrm{~min}$ ) at the Troms latitude. The regularity of the pulsations decreases with increasing latitude north of Troms $\phi$.

Figure A2 shows Ny Alesund photometer observations within the interval 10401145 UT. A quasi-periodic sequence of auroral intensifications (1100, 1110 1120,1130 UT) and subsequent poleward motions are observed after the initial event near 1045 UT. The intensifications appear to the south of the background aurora, which is consistent with a source plasma near the LLBL/PS interface. The optical recurrence period $(\sim 10 \mathrm{~min})$, as seen from the photometer data, is larger

7. JAN. 1988

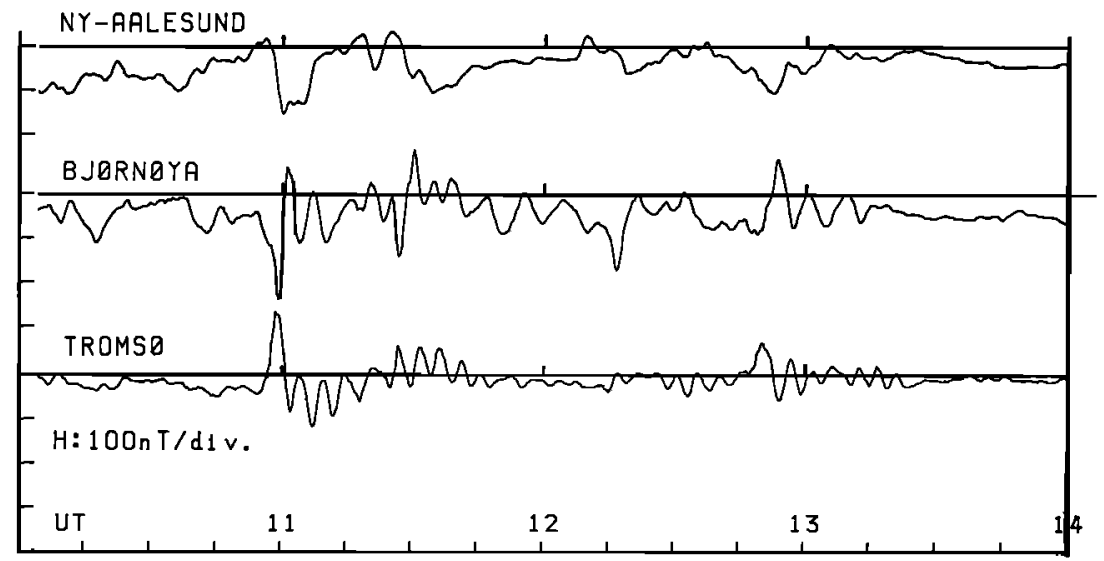

Fig. A1. H-component magnetograms from

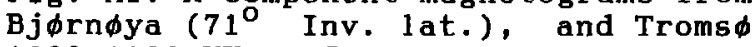
Ny Alesund $\left(75.6^{\circ}\right.$ Inv. 1at.), 1000-1400 UT on January 7, 1988. 


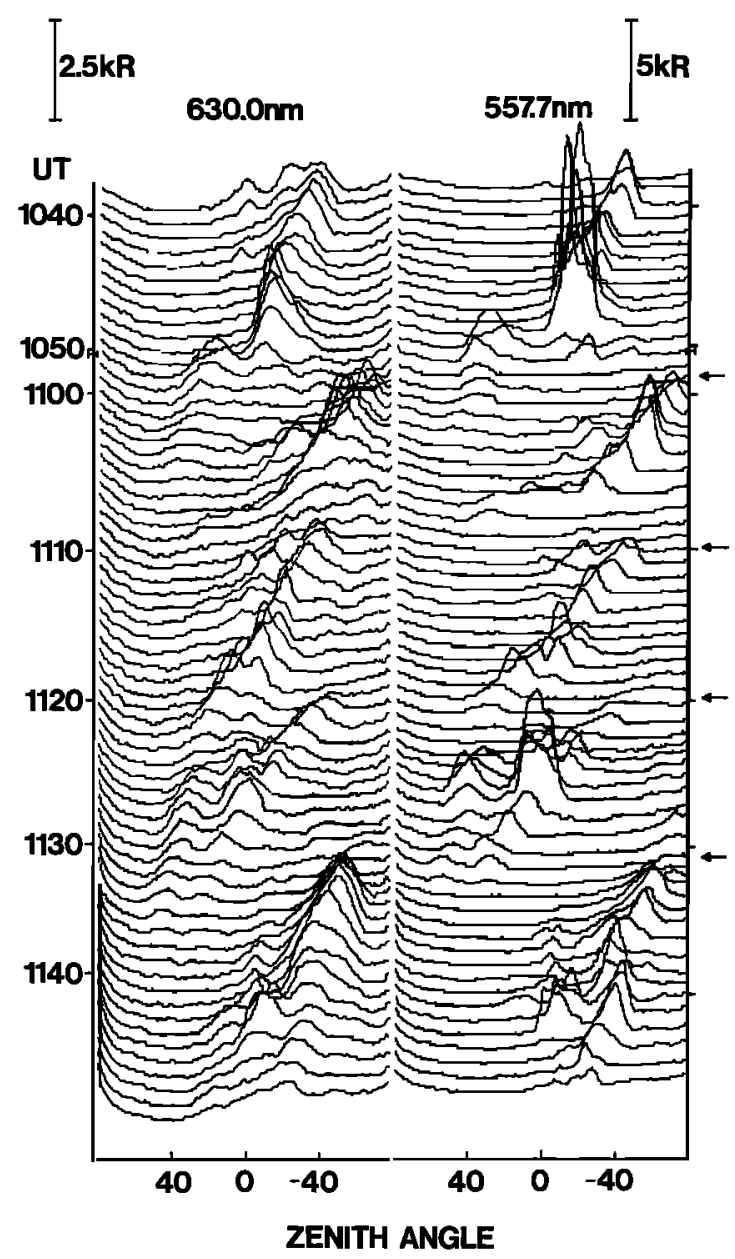

Fig. A2. Stacked plot of Ny A1esund meridian-scanning photometer traces (630.0 and $557.7 \mathrm{~nm}$ ) for the 1040-1145 UT interval on January 7,1988 . A sequence of four intensifications between 1100 and 1140 UT has been marked by arrows.

than the period of magnetic field oscil1ations ( $\sim 5 \mathrm{~min})$.

The two parameters in question may not be directly related. The optical structures are moving in longitude, possibly associated with a boundary layer wave. The harmonic geomagnetic field oscillations are centered on lower L-she11s.

The mechanisms for modulations in precipitating particle fluxes on cleft field 1 ines are not wel1 known at present. Potemra et al. (submitted manuscript 1989) suggested that large-scale waves in the boundary 1 ayer can modulate particle precipitation/auroral forms in the post-noon sector and excite resonant geomagnetic field oscillations on Lshells inside the inner edge of the region 1 Birkeland current.

The sharp onset of the January 7,1988 event indicates an external trigger pulse, probably an abrupt solar wind dynamic pressure variation (cf. Sibeck et al., 1989; Farrugia et al., 1989). In the oresence of a density gradient in the boundary layer a compressional perturbation at the magnetopause drives an incompressible flow with associated fieldaligned currents that will set up an electric field and flow system in the ionosphere. The ionospheric response is in some respects similar to that predicted for FTEs (cf. Southwood and Kivelson, 1990; L.C. Lee, Generation of field aligned currents by pressure pulses in the magnetosphere, submitted to Geophysical Research Letters, 1989). Furthermore, "the field aligned current response will contain longer lived oscillations when the dominant frequencies of the source spectrum match the local field line resonances."

Figure A3 shows H-component magnetograms for a 4-hour period that includes the optical sequence (1015-1050 UT) discussed in the main text. In this case the magnetic pulsations are much weaker and a clear onset of enhanced activity is not observed. A closer inspection of pulsation magnetometer data from $\mathrm{Ny}$ Alesund reveal a significant level of $\mathrm{PC}$ pulsations with intermittent Pi-type activity superposed, from early prenoon hours onwards. The Pc 5 pulsations recorded in Troms show a maximum in the prenoon hours (0600-0900 UT) on this day. Oscillations with about a $10 \mathrm{~min}$ period are observed in the Bjфrnфya records between 0900 and 1000 UT.

On the basis of the magnetic and optical differences between the January 7,1988 and the January 9, 1989 1400-1500 MLT events, care should be advised before drawing the conclusion that both phenomena are related to the same boundary layer process. On the other hand, the similarities between the two cases tell us that boundary waves should not be excluded as a possible source of the auroral/radar event sequence discussed in the main text of this paper. One may argue that on January 9, 1989 a largescale boundary wave (with a near 10-min

\section{JAN. 1989}

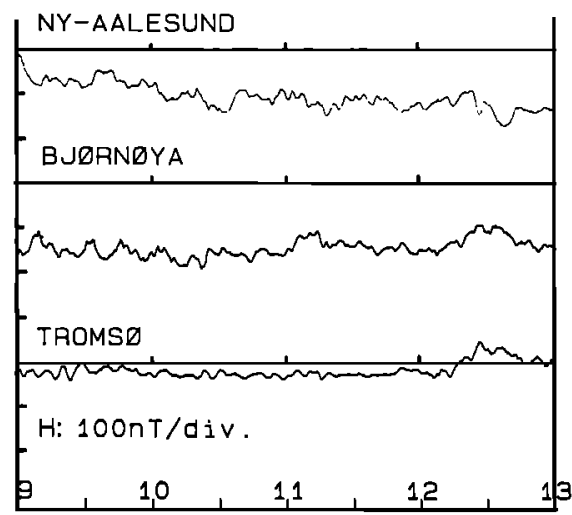

Fig. A3. H-component magnetograms from Ny

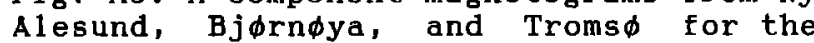
0900-1300 UT interval on January 9, 1989. 
period) was driving the optical sequence and the moderate magnetic field oscillations, whereas in the January 7,1988 case, the source of the impulse at 1050 UT may have set the magnetosphere ringing at a 5.5-min period and may also have 1 aunched a large-scale LLBL wave at a longer period (cf. the optical data).

Acknowl edgments.

The authors are grateful to A. Brekke/B. Holmeslet, University of Troms for ground magnetometer data used in this paper. We also thank V.N. Davda for plotting software for the EISCAT data and A. Egeland for organizing the optical observation program on Svalbard. Informative discussions with T.A. Potemra are highly appreciated. We thank the Director and staff of EISCAT for their assistance: EISCAT is supported by research councils of France (CNRS), West-Germany (MPG), Norway (NAVF), Sweden (NFR), Finland (SA), and the UK (SERC). Thanks are also due to the Norwegian Polar Research Institute and NAVF for the support to the optical observation campaign at Ny Alesund.

The Editor thanks $K$. Schlegel for his assistance in evaluating this paper.

\section{References}

Baumjohann, W., and G. Paschmann, Solarwind-magnetosphere coupling: Processes and observations, Phys. Scr. T, 18, $61-72,1987$.

Bythrow, P. F., M. A. Doyle, T. A. Potemra, L. J. Zanetti, R. E. Huffman, C.I. Meng, D. A. Hardy, F. J. Rich, and R. A. Heelis, Multiple auroral arcs and Birkeland currents: Evidence for plasma sheet boundary waves, Geophys. Res. Lett., 13, 805-808, 1986.

Bythrow, P. F., T. A. Potemra, R. E. Erlandson, L. J. Zanetti, and D. M. Klumpar, Birkeland currents and charged particles in the high-latitude prenoon region: A new interpretation, J. Geophys. Res., 93, 9791-9803, 1988 .

Chaloner, C. P., D. R. Lepine, D. S. Ha 1 1, D. A. Bryant, F. S申raas, K. Brфnstad, W. Stüdemann, B. Wilken, G. Kremser, J, F, Fennel, B. Blake, R. Kaga, and R. Lundin, The formation of boundary layers by the entry of lowenergy electrons and energetic ions into the Earth's magnetosphere, Smal1Scale Plasma Processes in the Solar Chromosphere/Corona, Interplanetary Magnetospheres, Proceedings of the 21 st ESLAB Symposium June 22-25, 1987 , Bolkesjф, Norway, ESA Spec. Publ. 275, p. 51, ESTEC, Eur. Space Agency, Nordwijk, The Netherlands 1987.

Cowley, S. W. H. , The cause of convection in the Earth's magneto-sphere: A review of developments during the IMS, Rev. Geo-phys. , 20, 531-565, 1982.

Cowley, S. W. H., Solar wind control of magnetospheric convection, Achievements of the International Magnetospheric study IMS, ESA Spec. Publ. 217, pp. 483-494, ESTEC, Eur. Space Agency, Noordwijk, Netherlands, 1984.

Cowley, s. W. H., The impact of recent observations on theoretical understanding of the solar wind-magnetosphere interactions, J. Geomagn. Geoelectr., 38, 1223-1256, 1986.

Elphic, R. C., Multipoint observations of the magnetopause: Results from ISEE and AMPTE, Adv. Space Res., $8(9), 223-$ 238,1988 .

Erlandson, R. E., L. J. Zanetti, T. A. Potemra, and B. F. Bythrow, IMF $B_{y}$ dependence of region 1 Birkeland currents near noon, J. Geophys. Res., 93, 9804-9814, 1988 .

Evans, D. S., The characteristics of a persistent auroral arc at high latitude in the 1400 MLT sector, in The Polar Cusp, NATO ASI Ser. C, vol. 145, edited by J.A. Holtet and A. Egeland, pp. 99-109, D. Reidel, Hingham, Mass., 1985.

Farrugia, C. J., M. P. Freeman, S. W. H. Cowley, D. J. Southwood, M. Lockwood, and $A$. Etemadi, Pressure-driven magnetopause motions and attendant response on the ground. planet. Space Sci., 37, 589-607, 1989 .

Heikkila, W. J., T. S. Jørgensen, L. Lanzerotti, and C. G. Maclennan, A transient auroral event on the dayside, J. Geophys. Res., 94, 15,291$15,305,1989$.

Iijima, T. and T. A. Potemra, Large-scale characteristics of field-aligned currents associated with substorms, J. Geophys. Res., 83, 599-615, 1978.

Lockwood, M. and K. J. Winser, On the determination of ion temperature in the auroral F-region ionosphere, Planet. Space Sci., 36, 1295-1304, 1988 .

Lockwood, M. , S. W. H. Cowley, H. Todd, D. M. Willis, and C. R. Clauer, Ion flows and heating at a contracting polar cap boundary, Planet. Space Sci., 36, 1229-1253, 1988 .

Lockwood, M., P. E. Sandholt, and S. W. H. Cowley, Dayside auroral activity and magnetic flux transfer from the solar wind, Geophys. Res. Lett., 16, 33-36, $1989 \mathrm{a}$.

Lockwood, M. P. E. Sandholt, S. W. H. Cowley, and T. Oguti, Interplanetary magnetic field control of dayside auroral activity and the transfer of momentum across the dayside magnetopause, Planet. Space Sci., 37, 1347$1365,1989 \mathrm{~b}$.

Lockwood, M., K. Suvanto, K. J. Winser, S. W. H. Cowley, and D. M. Willis, Incoherent scatter radar observations of non-Maxwellian ion velocity distributions in the auroral F-region, Adv. Space Res., $9(5), 113,1989 \mathrm{c}$.

Lockwood, M., P. E. Sandho1t, A. D. Farmer, S. W. H. Cowley, B. Lybekk, 
and V. N. Davda, Auroral and plasma flow transients at magnetic noon, Planet. Space Sci., 38, 973-993, 1990.

Lui, A. T. Y., D. Venkatesan, G. Rostoker, J. S. Murphree, C. D. Anger, L.L. Cogger, and T.A. Potemra, Dayside auroral intensification during an auroral substorm, Geophys. Res. Lett..' $14,415-418,1987$.

Lui, A. T. Y., D. Venkatesan, and J. S. Murphree, Auroral bright spots on the dayside oval, J. Geophys. Res., 94, $5515-5522,1989$.

Lundin, R., Solar wind energy transfer regions inside the dayside magnetopause, II, Evidence for an MHD generator process, Planet. Space Sci., 32, 757770,1984 .

Lundin, R. On the magnetospheric boundary layer and solar wind energy transfer into the magnetosphere, space Sci. Rev., 48, 263-320, 1988 .

Lundin, R. and D. S. Evans, Boundary layer plasmas as a source for highlatitude, early afternoon, aurora 1 arcs, Planet. Space Sci., 33, 13891406,1985 .

Meng, C. $-I$, and R. Lundin, Auroral morphology of the midday oval, J. Geophys. Res., 91, 1572-1584, 1986.

Newel1, P. T. and C. -I. Meng, The cusp and the cleft/boundary 1 ayer: Low-

altitude identification and statistical local time variation, J. Geophys. Res., 93, 14,549-14,556, 1988 .

Newe11, P.T. and C.-I. Meng, On quantifying the distinctions between the cusp and the cleft/LLBL, in Electromagnetic coupling in the Polar clefts and Caps, NATO ASI Ser. C, vol. 278, edited by P.E. Sandholt and A. Egeland, pp. 87101, Kluwer Academic, Dordrecht, The Netherlands, 1989.

Nishida, A., Can random reconnection on the magnetopause produce the lowlatitude boundary layer? Geophys. Res. Lett., 16, 227-230, 1989 .

Nishida, A., Ionospheric signatures of the random reconnection on the dayside magnetopause, J. Atmos. Terr. Phys., in press, 1990.

Rostoker, G. and T. Eastman, A boundary layer mode1 for magnetospheric substorms, J. Geophys. Res., 92, 12,187$12,201,1987$.

Russell, C.T., and R.C. Elphic, ISEE observations of $f l u x$ transfer events at the dayside magnetopause, Geophys. Res. Lett., 6, 33-36, 1979.

Sandholt, P. E. , B. Jacobsen, B. Lybekk, A. Egeland, P. F. Bythrow, and D. A. Hardy, Electrodynamics of the polar cusp ionosphere; A case study, J. Geophys. Res.' 94, 6713-6722, 1989.

Sandholt, P. E., M. Lockwood, T. Oguti, S. W. H. Cowley, K. C. S. Freeman, B. Lybekk, A. Egeland, and D. M. Willis, Midday auroral breakup events and related energy and momentum transfer from the magnetosheath, J. Geophys. Res., 95, 1039-1060, 1990 .
Saunders, M. A., Possible Kelvin-Helmholtz waves driven by reconnection accelerated flows, Geophys. Res. Lett., 16, 1031-1034, 1989 .

sckopke, N., G. Paschmann, G. Haerende1, B. U. 0 . Sonnerup, S. J. Bame, T. G. Forbes, E. W. Hones, Jr., and C. T. Russe11, structure of the low latitude boundary layer, J. Geophys. Res., 66 , 2099-2110, 1981 .

Sibeck, D. G., W. Baumjohann, R. C. Elphic, D. H. Fairfield, J. F. Fenne11, W. B. Gai 1, L. J. Lanzerotti, R. E. Lopez, H. Luehr, A. T. Y. Lui, C. G. Maclennan, R. W. McEntire, T. A. Potemra, T. J. Rosenberg, and $K$. Takahashi, The magnetospheric response to 8-min period strong-amplitude upstream pressure variations, $\mathrm{J}$. Geophys. Res., 94, 2505-2519, 1989.

Song, Y. and R. L. Lysak, Current dynamo effect of 3-D time-dependent reconnection in the dayside magnetopause, Geophys. Res. Lett., 16, $911-914$, 1989 .

Southwood, D. J., The ionospheric signature of $f l u x$ transfer events, $\mathrm{J}$. Geophys. Res., 92, 3207-3213, 1987.

Southwood, D. J. and M. G. Kivelson, The magnetohydrodynamic response of the magnetospheric cavity to changes in solar wind pressure, J. Geophys. Res., 95, 2301-2309, 1990 .

St. Maurice, J.-P. and R. W. Schunk, Ion velocity distributions in the highlatitude ionosphere, Rev. Geophys., 17, 99-134, 1979.

Suvanto, K., M. Lockwood, K. J. Winser, A. D. Farmer, and B. J. I. Bromage, Analysis of incoherent scatter radar data from non-Maxwellian F-region plasma, J. Atmos. Terr. Phys., 51, 483-495, 1989 .

van Eyken, A. P., H. Rishbeth, D. M. Willis, and S. W. H. Cowley, Initial EISCAT observations of plasma convec$t$ ion at invariant latitudes $70-77^{\circ}$, J. Atmos. Terr. Phys., 46, 635-641, 1984 .

Willis, D.M., M. Lockwood, S.W.H. Cowley, A.P. van Eyken, B.J.I. Bromage, H. Rishbeth, P.R. Smith, and S.R. Crothers, A survey of simultaneous observations of the high-latitude ionosphere and interplanetary magnetic field with EISCAT and AMPTE-UKS, J. Atmos. Terr. Phys. 48, 987-1008, 1986.

A.D. Farmer and $M$. Lockwood, Rutherford Appleton Laboratory, Chilton, Didcot, OX11 OQX, United Kingdom. B. Lybekk and P.E. Sandholt, Department of Physics, University of Oslo, P.0. Box 1048, Blindern,

0316 OSLO 3 , Norway.

(Received January 30, 1990 ; revised May 8, 1990 ; Accepted June 13, 1990.) 